\title{
Handcuffs for the Grabbing Hand? Media Capture and Government Accountability
}

\author{
Timothy Besley and Andrea Prat \\ Department of Economics and STICERD \\ London School of Economics and Political Science \\ Houghton Street \\ London WC2A 2AE
}

August 4, 2005

$\mathrm{PEPP} / 7$

July 2005
Political Economy and Public Policy Series The Suntory Centre Suntory and Toyota International Centres for Economics and Related Disciplines

London School of Economics and Political Science Houghton Street

London WC2A 2AE

Tel: (020) 79556674

(C) The author. All rights reserved. Short sections of text, not to exceed two paragraphs, may be quoted without explicit permission provided that full credit, including $\mathbb{C}$ notice, is given to the source 


\title{
Handcuffs for the Grabbing Hand? \\ Media Capture and Government Accountability*
}

\author{
Timothy Besley and Andrea Prat \\ Department of Economics and STICERD \\ London School of Economics and Political Science \\ Houghton Street \\ London WC2A 2AE
}

August 4, 2005

\begin{abstract}
It has long been recognized that the media play an essential role in government accountability. However, even in the absence of censorship, the government may influence news content by maintaining a "cozy" relationship with the media. This paper develops a model of democratic politics in which media capture is endogenous. The model offers insights into the features of the media market that determine the ability of the government to exercise such capture and hence to influence political outcomes.
\end{abstract}

*We are grateful to Silvia Pezzini for research assistance and to Carolee McLeish and Simeon Djankov for providing us with data. We thank Ben Bernanke and two anonymous referees for comments. We have also received helpful advice from Stephen Coate, Torsten Persson, Juan Pablo Rud, David Stromberg and a number of seminar participants. 


\section{Introduction}

For over two centuries, political thinkers have recognized that the media play an essential role in democracy. Thomas Jefferson famously stated: "The basis of our governments being the opinion of the people, the very first object should be to keep that right; and were it left to me to decide whether we should have a government without newspapers or newspapers without a government, I should not hesitate a moment to prefer the latter. But I should mean that every man should receive those papers and be capable of reading them." (Jefferson [18]) Jefferson's views are enshrined in the First Amendment of the US Constitution which - among other things - categorically prohibits Congress from passing laws that abridge the freedom of the press. As countries around the world transition from autocracy to more or less democratic forms of government, they tend to affirm press freedom in equally strong terms. For instance, the 1993 Constitution of the Russian Federation (article 25.1) proclaims that: "The freedom of the mass media shall be guaranteed. Censorship shall be prohibited."

But is formal media freedom enough to guarantee the free press that Jefferson envisaged? Russia is a case in point. Despite the lack of old-fashioned preemptive censorship, the Russian media are gravely hindered in other ways (Freedom House [12]). All national broadcasters are now owned by state-controlled companies. Most national newspapers are in the hand of a small number of wealthy individuals who are vulnerable to political pressure. It is no surprise that the Russian media provide a sympathetic and sometimes incomplete account of government behavior. Freedom House reports a not-dissimilar combination of formal press freedom and substantial political influence in several other democracies around the world, from Thailand to Italy, from India to Mexico. Since non-coercive media capture is such a widespread phenomenon, development and politics scholars should ask themselves what its determinants and consequences are.

This paper provides a simple theoretical framework to discuss how and when government captures media and what affect this has on political outcomes. Our starting point is 
a canonical political agency model (Barro [3], Ferejohn [10]). Voters use available information to decide whether to keep the current party in power or replace it with the opposition. The innovation of the present model is that information is provided endogenously by the media industry.

Each media outlet faces two possible sources of profit - commercial profit and profits from collusion with government. The former are broadly audience-driven. They can take the form of sales, subscriptions, advertising, depending on the specific medium under consideration. Audiences increase if the media outlet reports interesting information. Profits from collusion with government are various. At one extreme are direct monetary payments (bribes) of the kind that were reputedly common in Peru during Alberto Fujimori's government. ${ }^{1}$ They could, however, take a more subtle and indirect form of influence such as an administrative decision or a legislative intervention that benefits a firm controlled by the media owner. For instance, until 2003 two of the top three Italian national newspapers were controlled by the FIAT group, who could benefit from a restriction on car imports from Asia, a subsidy for new car purchases, or large investments in road construction (relative to comparable countries). ${ }^{2}$

The extent of media capture through such means is endogenous in our model. This, in turn, affects the voters' information and hence their voting decisions. This provides the link between media capture and government accountability.

The paper begins with the simplest possible setting - an exogenously given number of media outlets, a homogenous electorate, and an exogenously given information gathering

\footnotetext{
${ }^{1}$ See McMillan and Zoido [20] for an interesting account of media corruption in Peru. Montesino insisted on keeping detailed records, either written or videotaped, of his transactions with judges, politicians, and the media. The amounts paid to the media were about one hundred times larger than those paid to judges and politicians. On this basis, McMillan and Zoido argue that, by revealed preference, the media exercised the strongest check on government.

${ }^{2}$ All three of those policies were indeed in place at various stages of the Italian post-war history. The two newspapers, La Stampa and Corriere, have generally been regarded as pro-government or at least non-adversarial, independent of the party in office.
} 
technology. For this case, we show that:

1. Media pluralism provides effective protection against capture. Even in the absence of any horizontal differentiation among media outlets, the existence of a large number of independent media organizations make it less likely that the government controls news provision in equilibrium. Every time the government pays an outlet to suppress its information, the commercial revenue of the other outlets goes up because they face less competition on the commercial side. If the government wants to buy out all the media, it has to pay each of them as if it were a monopoly provider of unbiased information.

2. Independent ownership reduces capture. While this is a commonly heard statement, our model leads to a precise definition of independence. The degree of independence of the media is given by the difficulty with which the state is able to transfer resources to the media. The higher the transaction cost between the government and the media industry, the less likely that in equilibrium the industry is captured. In the next section, we will examine in more detail how our results on transaction costs can be used to evaluate the effect of different modes of ownership on media independence. We also draw out implications for the optimal regulation of media ownership.

3. Media capture affects political outcomes. Our retrospective voting model leads to predictions on how government control of the news affects the equilibrium features of the political system. Media capture has two negative effects on the utility of voters. There is a moral hazard component: elected politicians are more likely to engage in rent extraction in the knowledge that they are less likely to get caught. There is also an adverse selection part: intrinsically bad politicians are less likely to be identified and thus replaced. This sorting failure leads to a prediction on one important observable: the presence of media capture reduces political turnover.

Putting together the three previous points, our model establishes a link between observ- 
able features of the media industry (concentration and ownership) and observable political outcomes (capture, corruption, and turnover).

These conclusions are reached in an extremely stylized model. We complicate the analysis in a number of directions to demonstrate both the robustness of the findings and to derive additional implications. There are four main complications. First, we study the implications of moral hazard (rent extraction, corruption, etc...) as well as adverse selection. We discuss why this yields a non-monotonic relationship between media independence and the probability that the media reports bad news about the incumbent. Scandal-free countries have either an extremely independent media industry or an extremely pliable one. Second, we discuss what happens when the entry into the media industry is endogenous, i.e. potential entrants can become active by paying a fixed cost. Reducing barriers to entry in the media industry has a positive effect on corruption, turnover, and media capture. Third, we consider a model in which each outlet chooses how much to invest in monitoring technology (e.g. the number of reporters). We demonstrate that in equilibrium the media industry is vertically differentiated, with a handful of high-quality media organizations and a "tail" of outlets with low-monitoring ability. We show why in this world it is only the high quality media that gets captured. Moreover, media investments in monitoring are, in part, "rewarded" by the rents that they receive from government capture. Finally, we consider explicitly the consequences of less crude forms of media capture other than outright bribery such as rationing access to future news.

The current paper fits into an emerging literature on the role of the media in shaping economic and political outcomes. ${ }^{3} \quad$ For example, Besley and Burgess [5] discuss how newspaper circulation in India is correlated with dispersion of food aid and calamity relief. Stromberg [28] shows that New Deal spending across counties in the U.S. was correlated with radio ownership. Djankov et al. [7] demonstrate how state ownership of the media

\footnotetext{
${ }^{3}$ Hamilton [17] provides an extensive and systematic discussion of the economics of mass media. See also World Bank [29] for collected works on the role of the media in economic development.
} 
is related to various measures of poor government performance. Gentzkow and Shapiro [14] use data from nine predominantly Muslim countries to study the effect of media exposure on citizens' attitudes towards the United States. Gentzkow [13] shows that the development of broadcasting in the United States between 1960 and 1996 can explain 50\% of the decline in voter turnout in those years. Gentzkow, Glaeser, and Goldin [15] examine the changes in the U.S. newspaper industry that occurred between 1870 and 1920 and relate them to the reduction of corruption in US politics in the same period. Prat and Stromberg [23] use panel evidence from Sweden to measure the effect of the introduction of commercial broadcasting on voter information and turnout. In a nonpolitical context, Dyck and Zingales [8] present evidence consistent with a quid pro quo relationship between newspapers and corporations. ${ }^{4}$

The plan of the paper is as follows. Section 2 presents the baseline model and proves the core results of the paper. It then discusses the link between the model and the facts. Section 3 extends the baseline model in four directions. Finally, Section 4 concludes with a look at potentially interesting research questions and policy issues.

\section{The Baseline Model}

The aim is to produce the simplest possible model to generate the main insights. The model combines elections with a role for the media as information providers where capture by government is possible.

We use a two-period retrospective voting model. In the first period an incumbent is exogenously in power. There are two possible types $\theta \in\{b, g\}$ with $\operatorname{Pr}(\theta=g)=\gamma$, where $g$ stands for "good" and $b$ for "bad". A good incumbent delivers a benefit of one to voters while a bad incumbent generates a payoff of zero. At the beginning of time, an incumbent

\footnotetext{
${ }^{4}$ Other authors (Groseclose [16] and Puglisi [24]) use news content analysis to measure the extent of media bias.
} 
is selected who is good with probability $\gamma$. The baseline is a pure adverse-selection model where the policy outcome is a function solely of the politician's type. The latter can be interpreted either as intrinsic ability to produce public goods or as "honesty" where a dishonest incumbent steals resources from voters.

To make the problem interesting, we suppose that voters do not observe their payoffs at the time of the re-election decision. This is reasonable if some of the incumbent's policies have long-term consequences such as with fighting a war or investing in infrastructure.

There are $n$ active media outlets such as newspapers or TV stations. If the incumbent is good, the media observe no verifiable information. If the incumbent is bad, then with probability $q \in[0,1]$, they receive a verifiable signal to this effect. In practice, the parameter $q$ depends on technological and cultural characteristics and also on institutional variables such as the existence of censorship, the effectiveness of libel laws, and the extent of privacy protection regulation. We assume that only verifiable information can be printed.

Implicit in this informational setup are three assumptions. First, news cannot be fabricated. If we allowed the media to print uncorroborated news, and we wanted to maintain the assumption that voters are rational, we would need to get into a complex signalling game. Second, signals can only be bad. We could easily extend the model to have both good and bad signals, as long as the probability of good signals is lower than that of bad ones. Obviously, the incumbent would never want to suppress a good signal. ${ }^{5}$ Third, all media have the same information. This restriction is imposed for analytical convenience and will be relaxed in the next section.

The $n$ media outlets are identical and their payoff depends on two components: audiencerelated and policy-related revenues. The former revenues are important for for-profit media (sales, subscriptions, advertising receipts, cable fees, etc..) but they may also be relevant

\footnotetext{
${ }^{5}$ The crucial assumption is that not having a signal increases the probability that the incumbent is good. If this were not the case, a politician who manages to suppress bad information would still not be re-elected, and media capture would not occur in equilibrium.
} 
for non-profit or state-owned media if their mission includes reaching as many viewers as possible. Viewers prefer informative news. We assume that they divide themselves equally among the media outlets that are reporting news. The audience-related revenue of an outlet is normalized to zero if the outlet has no news and it is $\frac{a}{m}$ if it has news, where $a$ is a parameter that represents the maximum potential audience-related benefit and $m$ is the number of outlets that are reporting news. If at least one outlet has informative news, then all voters become informed. ${ }^{6}$

We allow incumbents to manipulate news. This is modeled as a bargaining game between the media and the politician. Since news cannot be fabricated, the only strategy available to politicians is to hide bad news. The bargaining game works as follows. The incumbent can make each outlet $i$ a non-negative monetary offer of $t_{i}$. A media outlet that accepts this offer suppresses his signal about the politician's type. Offers are simultaneous and private: the offer made to outlet $i$ is not observed by voters or by the other outlets. ${ }^{7}$ A transfer $t_{i} \operatorname{costs} t_{i}$ to the incumbent but yields $\frac{t_{i}}{\tau}$ to media outlet $i$. The parameter $\tau \in[0, \infty)$ is a transaction cost. The incumbent gets $r-\sum_{i \in I} t_{i}$ if she is re-elected and $-\sum_{i \in I} t_{i}$ if she is not, where $I$ is the set of media outlets who accept her offer.

Transfers in this setting can be interpreted in a wide sense. They range from direct instruments such as the cash bribes documented by McMillan and Zoido [20] to more subtle forms of influence such as enacting regulation that benefits firms owned by the same company that owns the media outlet. The cost of a transfer for the incumbent may be interpreted as the loss in terms of money, energy, or reputation that she has to incur to

\footnotetext{
${ }^{6}$ Neither of these specific assumptions is essential for the analysis. The functional form $\frac{a}{m}$ is assumed to get a simple closed-form solution, but the gist of the results depend only on the fact that audience-related revenues are decreasing in $m$. A model where not all voters become informed is available in the Additional Material section.

${ }^{7}$ The Appendix shows that the assumption that the incumbent's offer is not observed by other outlets is not crucial. If outlets are able to observe the offers that the incumbent makes to other outlets, the results go through as stated. See the discussion in footnote 24 on page 30.
} 
generate that transfer. The variable $\tau$ captures the existence of institutional transaction costs between the incumbent and the media. Legislative constraints and the risk of judicial prosecution may limit the channels through which the politicians can transfer funds to media. In the case where $\tau=\infty$, it is impossible for the policy maker to affect the revenues of the media.

We expect transactions costs to depend in reality on the form of media ownership. State-owned media seem likely to have the lowest transaction costs (unless they have a governance structure that guarantees actual independence such as quasi-independent news organizations like the BBC). Privately owned media are most likely to receive benefits if their owners (families, trade unions, industrial groups, etc.) have homogeneous interests. Cross-ownership of the media with other activities may be important too. For example, a broadcaster with diverse business interests may receive transfers through policy choices that are favorable to their non-media interests. We would expect independently-owned media to be more expensive to influence than media that are part of larger groups. Other things being equal, widely held private media are the hardest to influence. We might also expect media to be more independent when owned by foreign nationals who are less beholden to the government.

The timing of the game is as follows:

1. The incumbent's type $\theta \in\{b, g\}$ is realized $(\operatorname{Pr}(\theta=g)=\gamma)$. If $\theta=g$, media observe no signal $(s=\emptyset)$. If $\theta=b$, media observe $s=b$ with probability $q$ and $s=\emptyset$ otherwise. The incumbent observes the media signal and selects a transfer $t_{i} \geq 0$, for each outlet $i$.

2. Media outlet $i$ observes transfer $t_{i}$ and decides to accept or reject $t_{i}$. If it accepts, it reports $s=\emptyset$ and receives $\frac{t_{i}}{\tau}$. If it rejects, it reports the true signal.

3. Voters observe the signals reported by the media and vote for the incumbent or a challenger of unknown type. 
Two further assumptions are implicit in this set-up. First, the incumbent knows what signal the media have received. This is a useful simplification since it avoids an asymmetry between the outlets and the incumbent. It is arguably quite natural given that only verifiable signals can be printed - before making an offer the incumbent can always ask the media to reveal their evidence. Second, the incumbent makes her offers after the signals are realized. If she made her offers before, she would need to give each outlet $q a$ for certain instead of $a$ with probability $q$. As everybody is risk neutral and the probability $q$ is given, there would be no difference.

The equilibrium of the game has two components. The first is the bargaining game between the politician and the media. The second is the equilibrium in the election game. The bargaining game determines whether the media is an effective information provider in equilibrium. In situations where the media receives a transfer in exchange for silence we say that the media is captured, referring otherwise to the media being independent.

To model equilibrium in the media market, we focus attention on perfect Bayesian equilibrium restricted to pure-strategy equilibria in which voters use undominated strategies, i.e., always vote for the candidate they prefer. The equilibrium conditions for the media to be captured are given in: ${ }^{8}$

Proposition 1 Equilibrium in the media market may be one of two kinds:

1. If $n<\frac{r}{\tau a}$, the media industry is captured - each media outlet suppresses its information in exchange for a bribe $t_{i}=\tau a$.

2. If $n \geq \frac{r}{\tau a}$, the media industry is independent - each media outlet reports their information truthfully to voters.

\footnotetext{
${ }^{8}$ All proofs are in the Appendix. There it is shown that there is a unique pure-strategy perfect Bayesian equilibrium in which voters do not use dominated strategies. The restriction to pure strategies excludes coordination problems among broadcasters at stage 2. There may be mixed-strategy equilibria in which broadcasters and the incumbent randomize at the bribing stage. The restriction to undominated strategies avoids the well-known coordination problems among voters.
} 


\section{Proof. See Appendix.}

A key ratio according to this result is $r / \tau a$ - the level of rent enjoyed by an incumbent relative to the cost of silencing a media outlet. The Proposition says that media will be free if there is a large enough group of outlets relative to this ratio. Hence, ceteris paribus, media plurality is a good thing. Capture is most likely when rents from office holding are high. This is because the incumbent is willing to offer larger bribes to the media (other things being equal) when there is a larger rent associated with political survival. A more commercialized media (as measured by higher $a$ ) is a safeguard against media capture since it is more costly for the government to silence the media.

To understand the equilibrium structure of bribes when the media is captured, observe that, although the incumbent has all the bargaining power, it is not enough for her to reimburse each broadcaster for his lost revenues $-\frac{a}{n}$. In order to buy his silence, the incumbent has to pay him the amount it would get if it were the only broadcaster to bring news. A lower amount is not acceptable since the incumbent makes positive offers only if it knows that everybody is going to accept. Thus at least $a$ has to be offered to all active broadcasters, making the total cost of suppressing information $n \tau a$. The incumbent compares this with the forgone re-election benefit $r$ to determine whether suppressing the media is a good idea. The media sector is therefore captured if $n<\frac{r}{\tau a}$. The model makes precise why plurality in media ownership can serve as a guarantee of independence - having numerous outlets makes it harder for the incumbent to influence the whole industry.

There are two political consequences of media activism in this simple set-up: effects on turnover and effects on voter welfare. With captured media, bad politicians are never identified as voters have no ability to screen good from bad politicians. Their expected utility is therefore $\gamma$ - the probability that a randomly selected politician yields a benefit of one - in both periods. Turnover - defined as the probability that an incumbent is replaced by a challenger - is equal to zero (voters are indifferent between the incumbent 
and the challenger but they vote for the incumbent. $)^{9}$

If the media industry is not captured, then a bad incumbent is found out with probability $q$, in which case she is replaced with a challenger of unknown quality. Voters' expected utility is $\gamma$ in the first term and $\gamma+q(1-\gamma) \gamma$ in the second term and turnover is now $q(1-\gamma)$. Thus, in an equilibrium without captured media, turnover among politicians is higher than under captured media. It is also clear in this simple setting that voter welfare is higher.

Also, if we let $A$ be the sum of expected audience-related revenues for all outlets, we have that $A=q a$ when media are free and $A=0$ when media are captured. A by-product of capture is that the media industry alienates viewers by producing uninformative political news.

The next result maps this finding into the underlying parameters that determine whether media is free.

Proposition 2 Turnover of politicians, voter welfare, and total audience-related revenues are non-decreasing in $q, n, a$, and $\tau$.

Proof. See Appendix.

These effects come through two distinct channels. Greater media independence (high $\tau$ ), media commercialization (high $a$ ) and plurality (high $n$ ) influence whether or not the media is captured. Political transparency and efficient news production (high $q$ ) is valuable in societies with non-captured media, but does not directly influence media capture.

\footnotetext{
${ }^{9}$ If they voted for the challenger, a bad incumbent would have no incentive to buy off the media and the media will be informative, in which case the lack of signal would be a good signal. Thus, there cannot exist a pure-strategy equilibrium in which when there is no signal voters elect for the challenger for sure. A mixed-strategy equilibrium could exist in which when $s=0$ voters kick out the incumbent with positive probability. However, this equilibrium requires that information is completely suppressed (otherwise voters strictly prefer the incumbent). Hence, this equilibrium is analogous to the equilibrium with capture.
} 
While only suggestive, our results are consistent with some rudimentary facts gleaned from cross-sectional data. Ahrend [1] and Brunetti and Weder [6], for example, observe that there is a cross-country link between corruption and press freedom as measured by Freedom House. The latter measures in part the extent of media capture. ${ }^{10}$ To the extent that corruption is symptomatic of bad politicians being in office, our model is consistent with this finding.

Two further findings using data from Djankov et al. [7] are presented in Table 1. The table shows that corruption levels and tenure in office of political leaders is correlated with elements of media ownership, specifically the extent of state ownership and concentration in the ownership of newspapers. State ownership in this context can be interpreted as lowering transactions costs $\tau$. In columns (1)-(3), we compare the average number of years in office of the chief executive (typically President or Prime Minister) among countries with low and high state ownership of newspapers. High state ownership (more than $30 \%$ market share weighted) is associated with 7.21 years of increased tenure by the chief executive and the difference is strongly significant. This "effect" is equivalent to a one standard deviation increase in political longevity. State ownership of newspapers is also associated with a higher level of corruption, again with a significantly higher level for the countries with state ownership. To put this in perspective, an increase of 1 measured on the International Country Risk Guide (ICRG) 1 through 6 scale is equivalent to the difference between the score given to Peru and the United States. A similar set of findings for concentration in ownership is found in columns (4)-(6). Turnover is lower and corruption higher in countries with more concentrated media ownership. While such evidence crude and cannot be interpreted causally, it is encouraging that these facts are consistent with Propositions 1 and 2.

\footnotetext{
${ }^{10}$ For example, three key components of the freedom house index concern the exercise of legal, political and economic influence over the media.
} 


\section{Extensions}

We now explore a variety of extensions which assess the robustness of the results above and provide further insights.

\subsection{Moral Hazard}

Suppose now that the incumbent can choose how much rent extraction to engage in and that the probability that she is caught when doing so is increasing in the amount of rent that she consumes and the intensity of media activity. In this case the media can have a direct benefit to voters by curbing rent extraction. At the same time, this increase in honesty by politicians will tend to make screening good from bad politicians more difficult.

Formally, let the amount of rent that the incumbent appropriates be $y \in[0,1]$. The remainder, $1-y$, goes to voters. As before, there are two types of incumbents. Type $g$ has zero (or negative) benefit from rent and thus always chooses $y=0$. Type $b$ has a linear benefit from rent (and for simplicity we assume she has no re-election motive except the desire to get rent in the second term). The probability of detection now depends upon both $q$ and $y$. The more the incumbent appropriates, the easier it is for the media to catch her. Let $\Psi(y) q$ be the probability of detection given $y$. We assume that $\Psi^{\prime} \geq 0$, $\Psi^{\prime \prime}>0, \Psi(0)=0, \Psi^{\prime}(0)=0, \Psi(1)=1$, and $\lim _{y \rightarrow 1} \Psi^{\prime}(y)=\infty$. As before, $q \in[0,1] .{ }^{11}$ To illustrate these issues, we suppose that at least one media outlet is active and that there is no media capture. ${ }^{12}$

\footnotetext{
${ }^{11}$ As usual, a political accountability model with moral hazard and adverse selection has several interpretations. In the one we use, we interpret $\theta$ is honesty and $y$ is rent. However, $\theta$ could be disutility of effort and $y$ could be effort (the good type has no disutility for effort), or $\theta$ could be the degree to which the incumbent's policy preferences are similar to the voters' and $y$ the policy enacted (a bad politician is one with different tastes, who tries to introduce policies that voters do not like).

${ }^{12} \mathrm{~A}$ full-fledged model with moral hazard and the possibility of corrupt media is available from the authors on request.
} 
It is obvious that a good incumbent chooses $y=0$ in both terms. A bad incumbent appropriates $y=1$ in the second term. Thus, the utility for a bad type from being re-elected is 1 while the voters receive zero. In the first term, for a given $q$, a bad incumbent's rent extraction decision solves $\max _{y}\{y+1-\Psi(y) q\}$. This yields an optimal rent extraction level $-\hat{y}$ - satisfying

$$
\Psi^{\prime}(\hat{y}) q=1
$$

where the left-hand side is the marginal cost of rent extraction due to a higher probability of detection and the right-hand side is the marginal benefit of extra rent. It is now easy to check that

$$
\frac{d \hat{y}}{d q}=-\frac{\Psi^{\prime}(\hat{y})}{\Psi^{\prime \prime}(\hat{y}) q}<0 .
$$

Naturally enough, greater media activism reduces rent appropriation by politicians.

The presence of moral hazard makes the effect of active media on turnover ambiguous. To see this, first observe that turnover is now $\rho(q)=\Psi(\hat{y}(q)) q(1-\gamma)$. As $q$ increases, there are two effects. Holding rent extraction fixed, active media are more likely to detect rent appropriation as in the pure adverse selection model. This is the screening effect of active media. However, there is also an effect due to reductions in $y$ - more active media leads politicians to extract less from voters and makes it less likely that a bad incumbent is detected and removed from office. This is the discipline effect of media activity. This ambiguity can be seen analytically by observing that the sign of

$$
\rho^{\prime}(q)=\left(\Psi(\hat{y})+\Psi^{\prime}(\hat{y}) q \frac{d \widehat{y}}{d q}\right)(1-\gamma)
$$

cannot be determined in a general way.

To summarize, turnover is lower (higher) with increased monitoring if the discipline effect is more (less) important than the screening effect. While it is not possible make sharp predictions unless specific functional forms are assumed, we would expect turnover to be decreasing in monitoring only for high levels of $q$. This is because, if $q$ starts at a 
low level, an increase in it causes a large screening effect. Indeed, one can show that for a $q$ that tends to zero turnover must be increasing. ${ }^{13}$

Even though effects on turnover are ambiguous, voter welfare is still higher from media activism. To see this, observe that expected voter welfare is

$$
W(q)=2 \gamma+(1-\gamma)[1-\widehat{y}+\Psi(\hat{y}) q \gamma]
$$

The first term refers to the case where a good incumbent is elected in period one and is returned to power for sure since no rent seeking is ever detected. The second term refers to electing a bad incumbent who will extract $\widehat{y}$ and be caught with probability $\Psi(\hat{y}) q$, being replaced by a good incumbent with probability $\gamma$.

It is important to observe that a positive level of rent seeking by bad incumbents may be desirable to voters. This is because (in this model) rent-seeking is the only device for screening politicians. However, equilibrium rent seeking always exceeds the level desired by voters. This makes greater media activism valuable on the margin. ${ }^{14}$

The same argument for why voter welfare is increasing in $q$ implies that expected rents ${ }^{13}$ To show that $\lim _{q \rightarrow 0^{+}} \rho(0)=0$ and $\lim _{q \rightarrow 0^{+}} \rho^{\prime}(0)>0$, observe that $\lim _{q \rightarrow 0^{+}} \rho(q)=$ $\lim _{q \rightarrow 0^{+}} \Psi(\hat{y}(q)) q(1-\gamma)=0$ and $\lim _{q \rightarrow 0^{+}} \hat{y}(q)=1$. Obviously, it cannot be the case that $\lim _{q \rightarrow 0^{+}} \rho^{\prime}(0)<0$. however we can also exclude that $\lim _{q \rightarrow 0^{+}} \rho^{\prime}(0)=0$ as follows:

$$
\lim _{q \rightarrow 0^{+}} \rho^{\prime}(q)=\left(1-\lim _{q \rightarrow 0^{+}} \frac{\left(\Psi^{\prime}(\hat{y}(q))\right)^{2}}{\Psi^{\prime \prime}(\hat{y}(q))}\right)(1-\gamma)=(1-0)(1-\gamma)>0 .
$$

A simple functional form is: $\Psi(y)=1-\sqrt{1-y^{2}}$. In this instance, a bad incumbent chooses $\hat{y}(q)=$ $\frac{1}{\sqrt{1+q^{2}}}$, and turnover is

$$
\rho(q)=(1-\gamma)\left(1-\sqrt{\frac{q^{2}}{1+q^{2}}}\right) q
$$

It is now easy to check that for high enough $q$ this has a negative slope in $q$.

${ }^{14}$ To see this, note that the marginal benefit of rent to a voter is $\Psi^{\prime}(\hat{y}) q \gamma$ while the marginal cost is 1. The incumbent sets $\Psi^{\prime}(\hat{y}) q=1$ implying that the marginal cost must exceed the marginal benefit. Hence, the voter will always prefer a lower $y$ at the margin.

A more formal proof is available in the Appendix. 
are decreasing in media activity. To see this, observe that rents can be written as:

$$
R(q)=(1-\gamma)[1+\hat{y}-\Psi(\hat{y}) q \gamma]
$$

The incumbent always chooses a rent level below the expected rent maximizing level as he cares only about being re-elected himself rather than the total rents extracted from voters (by him and other bad incumbents). In general this makes him more cautious in rent seeking than rent maximization would imply. An increase in $q$ accentuates this effect (through the discipline effect) as well as reducing rents via the screening effect.

Putting this discussion together, we have:

Proposition 3 Suppose that there is both moral hazard and adverse selection. Then, the effect of media activity, as measured by $q$, has an ambiguous effect on turnover of incumbents. Voter welfare is increasing in $q$ and expected rents are decreasing in $q$.

This shows that results derived earlier are robust to incorporating moral hazard into the analysis. Voters prefer a more active media and rent appropriation is lower. This extension does, however, suggest that the relationship between turnover and media activity need not be monotonic. ${ }^{15}$

\subsection{Endogenous Media Entry}

The model is as in the baseline case except that the number of media outlets is now endogenous. ${ }^{16}$ We suppose that there is a large number of potential media outlets each of

\footnotetext{
${ }^{15}$ One could even go one step further by endogenizing the entry choice of politicians. A good politician receives a fixed ego rent, while a bad politician benefits from the rent he appropriates. Then, an increase in $q$ decreases the expected benefit of a bad type but does not change the incentive of a good one. We should then expect the pool of potential candidates to improve, that is, the ratio $\gamma$ should increase. This self-selection effect amplifies the positive consequences of an increase in monitoring activity.

${ }^{16}$ The assumption that there is no entry is perhaps less unrealistic for television compared to newspapers. The most common form of broadcasting is aerial television. At present, only in a handful of countries
} 
which can become active by paying a fixed cost of $c$. The latter can be thought of, for example, as the cost of hiring journalists, getting the appropriate technology and securing all the necessary authorizations.

The timing of the game is modified by adding a prior stage 0 in which each of the potential media outlets choose whether or not to enter. The entry decisions are made simultaneously and non-cooperatively. The rest of the game is as before. In particular, the outlets that have paid $c$ receive an informative signal with probability $q$. We assume that $q a>c$, so at least one outlet will find it profitable to enter.

As before, we focus on pure-strategy equilibria. ${ }^{17}$ This yields the following result describing when the media is captured:

Proposition 4 Equilibrium in the media market may be one of two kinds:

1. If $\bmod \left(\frac{q a}{c}\right)>\frac{r}{\tau a}$, the media industry is independent. The number of active media outlets is $m=\bmod \left(\frac{q a}{c}\right)$.

2. If $\bmod \left(\frac{q a}{c}\right)<\frac{r}{\tau a}$, the media industry is captured. The number of active media outlets is $m=\bmod \left(\frac{r}{\tau a}\right)$.

Whether or not the media is free is now determined by comparing two ratios: $\frac{r}{\tau a}$ and $\frac{q a}{c}$. The former is the maximum number of media the incumbent is willing to pay off, as in Proposition 1. The latter is the equilibrium number of entrants (disregarding integer constraints) under the assumption that the media industry is independent: it is derived from condition that equates the marginal revenue of the $m$ th outlet that enters (like the US) other forms of broadcasting such as cable or satellite are more widespread. Aerial television presents great barriers to entry, both technological because a network of transmitters is needed and administrative because a broadcasting license is needed. As a consequence, many countries, including several well-established market-oriented democracies, have been characterized by a small, and extremely stable, set of broadcasting organizations.

${ }^{17}$ This excludes the possibility of coordination failures at the entry stage. 
$\left(\frac{q a}{m}\right)$ with its marginal cost $(c)$. The last outlet that enters is then $m=\bmod \left(\frac{q a}{c}\right)$. If this number is greater than the number of maximum number of outlets that the incumbent is willing to pay off, then the media industry is free. If the media industry is free, the number of outlets is then $\bmod \left(\frac{q a}{c}\right)$. If, however, the industry is captured, the number is $\bmod \left(\frac{r}{\tau a}\right) \geq \bmod \left(\frac{q a}{c}\right)$. This is because, in a captured industry the marginal revenue of the $m$ th entrant is $a$ as long as $m \leq \bmod \left(\frac{r}{\tau a}\right)$.

In the baseline model we found that media plurality was an effective defense against capture. This result still holds with free entry, except that now plurality is a consequence of entry costs. The greater are barriers to entry, the more likely it is that the incumbent captures the media. It is straightforward to see from from Proposition 2 that an increase in the entry cost reduces political turnover and voter welfare.

From a practical standpoint, this extension shows why barriers to entry in the media market lead to more capture and worse political outcomes. This explains why restrictive entry policies in the media market, such as limits on foreign ownership, can have unfavorable consequences beyond the standard welfare losses that arise in standard markets.

\subsection{Endogenous Monitoring}

We now suppose that media quality is determined by investment decisions. We do so by assuming that the difficulty of detecting a bad type is a random variable. Sometimes a minimal amount of information gathering is enough. On other occasions, it is necessary to have sufficient resources in place to launch a journalistic investigation. Each media outlet chooses its monitoring capacity. We show that this set up will result in an equilibrium in which media outlets are vertically differentiated in terms of quality. This implies that media capture is now stochastic and dependent ex ante on the resources that are put into monitoring.

Formally, suppose that each media outlet can improve its monitoring ability by hiring talented journalists and/or providing them with better resources. Hence, outlet $i$ selects 
$q \in[0,1]$ at cost of $c(q)$, where $c(\cdot)$ is increasing, convex, and twice differentiable. ${ }^{18}$ There is a large group $n$ of media entrants who, at stage 0 , select their monitoring investments simultaneously and non-cooperatively. The difficulty of detecting the incumbent's type ex post is determined by the realization of a random variable $\nu$, which is uniformly distributed on the unit interval. An outlet with detection effort $q_{i}$ receives verifiable information that an incumbent is bad if $\nu \leq q_{i}$. The rest of the game is as in the baseline model. We now characterize the equilibrium vector of quality investments and the probability of media capture.

The number of informed media outlets depends on the realization of $\nu$. The incumbent will still want to buy off either all informed media outlets or none of them. In equilibrium the cost of buying off one broadcaster is $\tau a$. If $m$ is the number of informed media, then the incumbent chooses to bribe them if and only if $r \geq m \tau a$. This defines a maximum number of broadcasters $M=\bmod \left(\frac{r}{\tau a}\right)$ that the politician is willing to pay off. If more than $M$ broadcasters turn out to be informed, then the incumbent gives up and the media is not captured.

Without loss of generality, broadcasters can be indexed in order of decreasing technology, so that $q_{1} \geq q_{2} \geq \cdots \geq q_{n}$. The incumbent bribes the media if and only if $\nu>q_{M+1}$. There are thus three cases according to the realization of $\nu$. If $\nu>q_{1}$, no broadcaster is informed and the incumbent gets re-elected. If $q_{M+1}<\nu \leq q_{1}$, informed media are captured and the incumbent is also re-elected. Finally if, $\nu \leq q_{M+1}$, the media is not captured and the incumbent is removed from office.

In equilibrium, broadcasters fall into two categories. Those with $q>q_{M+1}$ are "potentially captured", i.e. have a positive probability of being bought off by government. Those with $q \leq q_{M+1}$ are always not captured and compete only for audience share. The equilibrium choices of $q$ are thus as follows:

Lemma 5 Let $M=\bmod \left(\frac{r}{\tau a}\right)$ and let $\hat{q}(k)$ be the unique $q$ such that $c^{\prime}(q)=\frac{a}{k}$. In

${ }^{18}$ Corner solutions are avoided if we also assume that $c(0)=c^{\prime}(0)=0$ and $\lim _{q \rightarrow 1} c^{\prime}(q)=\infty$. 
equilibrium, $q_{1}=\cdots=q_{M}=\hat{q}(1)$ and, for every $i \geq M+1, q_{i}=\hat{q}(i)$. A bad incumbent is removed from office with probability $\hat{q}(M+1)$.

The proposition describes a pure-strategy equilibrium which is unique up to a renumbering of media outlets. The choice of monitoring investment is determined by equating the marginal cost to the marginal revenue. If an outlet belongs to the potentially captured group, its marginal revenue is given by the monopoly profit of being bought off by the incumbent which is equal to $a$. If outlet $i$ belongs to the low $q\left(\leq q_{M+1}\right)$ group of media, its marginal revenue is audience-related and depends on how many outlets are printing news. It is equal, therefore, to $\frac{a}{i} \cdot 19$

Improved media efficiency can now be modeled as a fall in the cost of investing in monitoring. Thus, let $c(q)=\kappa C(q)$, where $\kappa$ is a positive number and the function $C(\cdot)$ has the regularity properties discussed above. The parameter $\kappa$ can be interpreted as the ease with which the media can make investments in quality, perhaps reflecting the degree of transparency in the operation of government.

Voter welfare and turnover are determined by the probability that a bad incumbent is not re-elected: $\hat{q}(M+1)$, which by Lemma 5 is implicitly defined by

$$
\kappa C^{\prime}(q)=\frac{a}{\bmod \left(\frac{r}{\tau a}\right)+1}
$$

This shows that $C^{\prime}(\hat{q}(M+1))$ is non-decreasing in $a$ and $\tau$, and non-increasing in $\kappa$. Note that an increase in $a$ has two effects, both positive: it increases the incentives for media to buy better monitoring technology and it increases the cost for the incumbent of buying off the media. As $C^{\prime}(q)$ is increasing in $q$, we have:

Proposition 6 Suppose the media choose their monitoring level endogenously. Turnover and voter welfare are non-decreasing in a and $\tau$, and non-increasing in $\kappa$.

\footnotetext{
${ }^{19}$ The proof of the lemma checks that (in this highly discontinuous problem) these intuitive first-order conditions are indeed sufficient for a pure-strategy equilibrium.
} 
The model with endogenous monitoring has an important practical implication. Suppose we compare two countries that are otherwise identical but one has an institutional environment that is more conducive to capture (lower $a$ or $\tau$, or higher $\kappa$ ). The latter country will have a media industry that is less vertically differentiated. It will have a larger number of outlets that are captured with positive probability in equilibrium (the $M$ of Lemma 5), which all have the same monitoring ability $\hat{q}(1)$. The intuition is simple. The marginal revenue of capture does not depend on the number of captured outlets, while the marginal commercial revenue is decreasing in the number of informative outlets. Hence, a captured media industry has less incentive to vertically differentiate itself.

In this respect, it is interesting to note that two of the countries with the oldest tradition of media freedom - the US and the UK - are also characterized by a strong degree of vertical differentiation A small number of titles (such as the New York Times and the Wall Street Journal in the US, or a hierarchy of "broadsheets" in the UK) command high respect and high prices, while a long lower tail (local newspapers in the US and tabloids in the UK) of low-quality dailies are given away almost for free. Our theory interprets this extreme vertical heterogeneity as a healthy sign that the press of these two countries is working for the audience rather than for the government. A much more worrying situation can be encountered in a country like Italy, which has traditionally lacked both the high-quality titles willing to engage in high-profile investigative journalism and the long lower tail which still constitutes a barrier to complete political capture.

\subsection{Bribing as Access}

In democracies with a well-established system of checks and balances, the government may find it difficult to make cash transfers to the media or to adopt policies that are blatantly biased in favor of a media company. However, it can still try to influence the media by offering selective access to politicians to friendly media outlets. For instance, the Prime Minister or President can grant an exclusive interview to one particular newspaper or 
television channel. If this is of interest to the public, then it increases the commercial revenues of the chosen outlet. We now investigate whether our core results are sensitive to modeling influence in this way. ${ }^{20}$

We make one change to the basic model. The government cannot make monetary transfers $t_{i}$ but it can promise outlet $i$ an "interview" denoted by $I_{i} \in\{0,1\}$, where 1 indicates that an interview is granted if outlet $i$ keeps quiet about embarrassing news. We assume that the commercial value of such an interview is decreasing in the number of outlets that have been granted the interview. Let $\hat{m}$ be the number of outlets that enjoy selective access - the additional profit deriving from the interview is $\pi(\hat{m})$ which is strictly decreasing in $\hat{m}$. We assume that granting interviews is not costly to the government. ${ }^{21}$

It is now straightforward to see that the government is able to silence the media if and only if $\pi(n)>a$. That is, for a media outlet, the benefit of being the one to break news must be less than the benefit of receiving an interview with the prime minister when all the other media outlets have been granted an interview as well. Thus we have:

Proposition 7 The media industry is captured if and only if $\pi(n)>a$.

As $\pi$ is decreasing in $n$, the risk of capture is reduced, as in the baseline model, when the number of media outlets increases. With low media concentration, being one of the many outlets with an "exclusive" interview with the prime minister is less attractive than being the only one to report an important piece of negative news. This analysis confirms that the basic idea of the analysis works for a wider class of influences on the media than pure bribery.

\footnotetext{
${ }^{20}$ Reich [26] contends that the current US admistration has received mostly positive coverage from the media also because "Bush's White House press operation has been one of the most disciplined and effective in American history - rewarding friendly reporters with access and scoops, freezing out unfriendly ones."

${ }^{21}$ The presence of a cost of granting interviews would make the effect of plurality stronger.
} 


\section{Conclusions}

The main contribution of this paper is to study the political economy of media capture. The model developed here produces a number of predictions on the relationship between features of the media industry, media capture and political outcomes that are consistent with cross-country facts.

Studying the role of the media in achieving government accountability gives a sense of why regulatory issues for the media sector go beyond standard competition policy concerns. Changes in the concentration level or in the ownership structure may affect welfare, not only through the traditional channel of consumer surplus (subscription prices, advertising rates, etc...), but also through effects on political accountability. A potential innovation in the media industry - such as the privatization of a state broadcaster, a relaxation of rules on private or foreign ownership, or a merger among hitherto separate media companies - must also be evaluated on the basis of its effect on the ability of the government to influence news production to its advantage. The model suggests two such dimensions. First, does a regulatory reform increase or decrease the number of independent news producers? Second, does it increase or decrease the transaction cost between the government and the outlets involved?

The analysis also sheds new light on the role of regulatory bodies. A recent OECD meeting of national regulators expressed a general consensus that media pluralism is of paramount importance but concluded that: "Competition authorities are often reluctant to include pluralism considerations in merger reviews or even advise concerning them. This reluctance is sometimes explained by referring to measurement difficulties, and a lack of synergies in terms of the expertise required to assess economic and pluralism effects. There are also concerns to safeguard a competition authority's independence from political pressure and to preserve its reputation for objectivity and even-handed dealings." (OECD [22]) Enabling regulators to act as an effective safeguard of media independence requires an operational criterion to evaluate the danger of capture and institutional protection 
against political pressure.

The analysis developed here is simple and much remains to be done to obtain a complete picture of the issues that arise in thinking about the media's role in modern societies from an economic point of view. It would be interesting, in particular, to relax the assumption that the media produce only hard information. In practice, journalists often possess information from unofficial sources (as in the Watergate scandal) or personal impressions. When presented with unverifiable information, readers must decide whether to believe it. This requires a dynamic model of reputation formation among media outlets. A first move in this direction is suggested by Gentzkow and Shapiro [14] who prove that profit-maximizing media outlets may slant their news towards readers' prior beliefs in order to appear more credible. However, an increase in media competition reduces bias.

Our model of capture has focused on media bias that is induced by political capture. However, three recent papers have shown that bias can come from other sources: reputational concerns of the media (the above cited Gentzkow and Shapiro [14]), a confirmatory cognitive bias of readers (Mullainathan and Shleifer [21]), and an ideological bias of reporters (Baron [2]). In the last two cases, concentration may have the opposite effect compared to the present paper and to Gentzkow and Shapiro: an increase in the number of independent media outlets can actually lead to an increase in the level of bias. ${ }^{22}$

But the main message remains clear. The formal safeguards of media freedom enshrined in law are no guarantee of a media sector that is free from political interference. Understanding the potential distortions that can arise in the behavior of the media and what makes them more prevalent is of both theoretical and practical interest.

\footnotetext{
${ }^{22} \mathrm{~A}$ previous version of this paper, available on request, extends the model to allow for ideologicallymotivated newspapers and voters. It shows that ideological polarization in the media may reduce capture by making it more expensive for the incumbent to silence the whole media industry (provided that voters are flexible in their choice of media).
} 


\section{References}

[1] Ahrend, Rudiger, [2000], "Press Freedom, Human Capital and Corruption," Working Paper

[2] David P. Baron [2004], "Persistent Media Bias," Research Paper No. 1845(R), Stanford Graduate School of Business.

[3] Barro, R. J. [1973]: "The control of politicians: An economic model," Public Choice, $14,19-42$.

[4] Beck, Thorsten, George Clarke, Alberto Groff, Philip Keefer, and Patrick Walsh, [2000], "New Tools and Tests in Comparative Political Economy: The Database of Political Institutions", The World Bank Development Research Group, Working Paper No. 2283.

[5] Besley, Timothy and Robin Burgess, [2002], "The Political Economy of Government Responsiveness: Theory and Evidence from India," Quarterly Journal of Economics, $117(4), 1415-1452$.

[6] Brunetti, Aymo, and Beatrice Weder, [2003], "A free press is bad news for corruption," Journal of Public Economics, 87(7-8), 1801-1824.

[7] Djankov, Simeon, Caralee McLeish, Tatiana Nenova, and Andrei Shleifer [2003], "Who Owns the Media?" Journal of Law and Economics 46(2), 341-382.

[8] Dyck, Alexander and Luigi Zingales [2003], "The Media and Asset Prices", in World Bank Institute, The Right to Tell: The Role of Mass Media in Economic Development, Washington DC: The World Bank.

[9] Feddersen, Timothy and Wolfgang Pesendorfer [1997], "Voting Behavior and Information Aggregation in Elections with Private Information," Econometrica, 65(5): 10291058. 
[10] Ferejohn, John [1986]: "Incumbent performance and electoral control," Public Choice, $50,5-25$.

[11] Freedom House, [2000], Press Freedom Survey 2000, available at http://www.freedomhouse.org/pfs2000.pdf.

[12] Freedom House, [2001], Press Freedom Survey 2001, available at http://www.freedomhouse.org/pfs2001.pdf.

[13] Matthew Gentzkow, [2004], "Television and Voter Turnout," working paper.

[14] Matthew Gentzkow and Jesse M. Shapiro, [2005], Media Bias and Reputation. Working Paper.

[15] Gentzkow, Matthew, Edward Glaeser and Claudia Goldin, [2004], "The Rise of the Fourth Estate: How Newspapers Became Informative and Why It Mattered," NBER Working Paper No. 10791.

[16] Groseclose, Timothy and Jeff Milyo [2003] "A Measure of Media Bias." Working paper.

[17] Hamilton, James T., [2003], All the News That's Fit to Sell: How the Market Transforms Information into News. Princeton: Princeton University Press.

[18] Jefferson, Thomas [1787] "The People are the only Censors ..." Letter to Edward Carrington, Paris, Jan. 16, 1787.

[19] La Porta, Rafael, Florencio Lopez-de-Silanes, Andrei Shleifer and Robert Vishny, [1998], "Law and Finance," Journal of Political Economy, 106(6), 1113-1150.

[20] John McMillan and Pablo Zoido, [2004], "How to Subvert Democracy: Montesinos in Peru," Working paper, Stanford University. 
[21] Mullainathan, Sendhil and Andrei Shleifer [2005], "The Market for News," forthcoming in the American Economic Review.

[22] OECD [2003], "Media Mergers", DAFFE/COMP(2003)16, Directorate for Financial, Fiscal, and Enterprise Affairs: Competition Committee, OECD. September 2003.

[23] Prat, Andrea and David Strömberg [2004], "The Political Economy of State Television." Working paper.

[24] Puglisi, Riccardo, [2004], "Being the New York Times: the Political Behaviour of a Newspaper," Working paper.

[25] Przeworski. Adam, Susan C. Stokes and Bernard Manin, [1999], Democracy, Accountability, and Representation, Cambridge: Cambridge University Press.

[26] Reich, Robert. "The honeymoon continues for George." The Observer, Sunday August $3,2003$.

[27] Segal, Ilya [1999], "Contracting with Externalities," Quarterly Journal of Economics, $114(2), 337-388$.

[28] Strömberg, David, [2004], "Radio's Impact on Public Spending," Quarterly Journal of Economics, forthcoming.

[29] World Bank Institute, [2003] The Right to Tell: The Role of Mass Media in Economic Development, Washington DC: The World Bank. 


\section{Appendix: Proofs of Propositions}

\section{Proof of Proposition 1}

The equilibrium strategies and beliefs are:

1. Voters believe

$$
\operatorname{Pr}(\theta=g)= \begin{cases}0 & \text { if } s=b \\ \gamma & \text { if } s=\varnothing\end{cases}
$$

2. Voters vote for the challenger if $s=b$ and re-elect the incumbent if $s=\varnothing$.

3. Outlet $i$ accepts $t_{i}$ if and only if $t_{i} \geq \tau a .^{23}$

4. The incumbent offers $t_{i}=\tau a$ to all outlets if: (a) outlets have observed $s=b$; (b) $n \tau a \leq r$. The incumbent offers 0 to all outlets otherwise.

It is easy to check that this is a perfect Bayesian equilibrium of the baseline game.

We now prove that this is the unique pure-strategy perfect Bayesian equilibrium in which voters do not play weakly dominated strategies (PSPBEW).

Begin with voter behavior. The only information voters receive is the signal $s$. Thus, their strategy can only be conditioned on $s$. Kicking out the incumbent if $s=b$ is a strictly dominant strategy. The only question is whether there can be a pure-strategy equilibrium in which the incumbent is kicked out if $s=\emptyset$. But this is impossible because if that were the case, the incumbent would not suppress information and hence the posterior when the voters observe $s=\emptyset$ would be strictly greater than $\gamma$, and voters should actually re-elect the incumbent whenever they observe $s=\emptyset$. Thus, in every PSPBEW the incumbent is re-elected if and only if $s=\emptyset$.

Now, consider the interaction between the incumbent and the outlets. We show that in every PSPBEW an informed outlet accepts $t_{i}>a$ and rejects $t_{i}<a$. First, the commercial

\footnotetext{
${ }^{23}$ Technically, we should also specify the belief of outlet $i$ on the offers made to other outlets, but this is not necessary because the reasoning below shows that the equilibrium strategy is essentially unique.
} 
revenue of $i$ cannot be higher than $a$. Thus, in any equilibrium $i$ must accept offers above a. Second, given any reply function on the part of outlets, in equilibrium the incumbent buys off either all the informed outlets or none of them. Suppose that there exists an equilibrium in which $i$ accepts an offer strictly below $a$. This must be an equilibrium in which all outlets are silenced. But then, if $i$ rejects the offer, it is the only outlet to break news and he gets $a$ : a contradiction. ${ }^{24}$

The fact that outlets accept $t_{i}>a$ and rejects $t_{i}<a$ means that in every PSPBEW the incumbent silences the media if $n \tau a<r$ and does not silence them if $n \tau a>r$.

We have thus shown that in every PSPBEW, players behave as in the equilibrium discussed above (with the proviso that if $n \tau a=r$, the incumbent may or may not silence the media).

\section{Proof of Proposition 3}

The ambiguity in the turnover effect is explained in the text. For voter welfare observe that

$$
\begin{aligned}
W^{\prime}(q) & =(1-\gamma)\left(\left(-1+\Psi^{\prime}(\hat{y}(q)) q \gamma\right) \frac{d \hat{y}}{d q}+\Psi(\hat{y}(q)) \gamma\right) \\
& =(1-\gamma)\left(\frac{\Psi^{\prime}(\hat{y})\left(1-\Psi^{\prime}(\hat{y}) q \gamma\right)}{\Psi^{\prime \prime}(\hat{y}) q}+\Psi(\hat{y}(q)) \gamma\right) \\
& =(1-\gamma)\left(\frac{\left(\Psi^{\prime}(\hat{y})\right)^{2} q(1-\gamma)}{\Psi^{\prime \prime}(\hat{y}) q}+\Psi(\hat{y}(q)) \gamma\right)>0
\end{aligned}
$$

where the third equality is due to the first order condition for the incumbent. The effect on expected rent is confirmed by observing that $R^{\prime}(q)=-W^{\prime}(q)$.

\footnotetext{
${ }^{24}$ The result that in every PSPBEW an informed outlet accepts $t_{i}>a$ and rejects $t_{i}<a$ holds also if the incumbent's offers are observed by all outlets. The line of reasoning above is entirely independent from the information that outlets have about transfers made to other outlets. Therefore, a PSPBEW of a game with offers that are public among outlets is identical to the equilibrium discussed above.
} 


\section{Proof of Proposition 4}

Stages 1, 2, and 3, are as in proof of Proposition 1. For stage 0, hold the entry choices of the other broadcasters fixed. Suppose that exactly $m-1$ broadcasters are entering. If $m \leq \frac{r}{\tau a}$, an additional broadcaster who enters receives expected revenue $q a$. Thus he enters if and only if $c \leq q a$ (and we assumed $q a>c$ ). If instead $m>\frac{r}{\tau a}$, the expected revenue is $\frac{q a}{m}$, and the broadcaster enters if $c \leq \frac{q a}{m}$. In this case, the equilibrium number of entrants is $m=\bmod \left(\frac{q a}{c}\right)$. If $\bmod \left(\frac{q a}{c}\right)<\frac{r}{\tau a}$, then, when $m-1=\bmod \left(\frac{r}{\tau a}\right)$, an additional broadcaster would get a negative revenue by entering, and the equilibrium $m$ is $\bmod \left(\frac{r}{\tau a}\right)$. If $\bmod \left(\frac{q a}{c}\right)>\frac{r}{\tau a}$, then the equilibrium $m$ is $\bmod \left(\frac{q a}{c}\right)$.

It is also easy to see that this is the only pure-strategy equilibrium of the entry game.

\section{Proof of Proposition 5}

Formally, the timing of the game is as follows:

1. Broadcasters choose their $q$ 's and incur cost $q$. Without loss of generality, index them in order of decreasing $q$.

2. The incumbent's type $\theta \in\{b, g\}$ is realized $(\operatorname{Pr}(\theta=g)=\gamma)$. The difficulty $\nu$ is realized. Broadcaster $i$ observes signal

$$
s_{i}= \begin{cases}b & \text { if } \theta=b \text { and } \nu \leq q_{i} \\ \emptyset & \text { otherwise }\end{cases}
$$

The incumbent observes $\nu$ and selects a transfer $t_{i} \geq 0$, for each broadcaster $i$.

3. Broadcaster $i$ observes $t_{i}$ and decides to accept or reject it. If he accepts, he reports $s=\emptyset$ and receives $t_{i}$. If he rejects, he reports the true signal. Signals cannot be fabricated.

4. Voters observe the signals reported by broadcasters and vote for the incumbent or a challenger of unknown type. 
The following is a pure-strategy perfect Bayesian equilibrium. $M=\bmod \left(\frac{r}{\tau a}\right)$ and let $\hat{q}(k)$ be the unique $q$ such that $c^{\prime}(q)=\frac{a}{k}$.

1. Broadcaster $i$ selects $q_{i}=\hat{q}(1)$ if $i \leq M$ and $q_{i}=\hat{q}(i)$ otherwise.

2. If the signal is good or $\nu \leq q_{M+1}$ or $\nu>q_{1}$, the incumbent offers no transfers. If the signal is bad and $\nu \in\left(q_{M+1}, q_{1}\right]$, the incumbent offers a transfer $t_{i}=\frac{a}{\tau}$ to all informed broadcasters.

3. An informed broadcaster accepts a transfer $t_{i}$ if and only if $t_{i} \geq a$.

4. Voters re-elect the incumbent if and only if $s=\emptyset$.

It is immediate to check that 2, 3, and 4 are best responses. Given 2, 3, and 4, we now check point 1 . Let $\left(\hat{q}_{1}, \ldots, \hat{q}_{n}\right)$ be the strategies of the $n$ outlets according to point 4 . Holding the other $q$ 's fixed, we consider a deviation $q_{i} \neq \hat{q}_{i}$ by player $i$. For $j=1, \ldots, n$, let

$$
k(j)=\left\{\begin{array}{ll}
j & \text { if } \quad j \geq M+1 \\
1 & \text { if } \quad j \leq M
\end{array} .\right.
$$

The payoff to an informed outlet, if $m$ outlets are informed is then written as $\frac{a}{k(j)}$.

Given $\nu$, let $w(\nu)$ be the highest $j \neq i$ such that $\nu \leq \hat{q}_{j}$. Then, given a realization $\nu$, the payoff of $i$ given $q_{i}$ is

$$
r\left(q_{i}, \nu\right)=\left\{\begin{array}{cll}
0 & \text { if } \quad q_{i}<\nu \\
\frac{a}{k(w(\nu)+1)} & \text { if } \quad q_{i} \geq \nu \text { and } w(\nu)<i \\
\frac{a}{k(w(\nu))} & \text { if } \quad q_{i} \geq \nu \text { and } w(\nu)>i
\end{array}\right.
$$

This is because, if $i$ is informed and $w(\nu)<i$, the informed outlets are $1, \ldots, w(\nu)$ plus outlet $i$. If instead $i$ is informed but $w(\nu)>i$, the informed outlets are $1, \ldots, i, \ldots, w(\nu)$.

The expected profit of $i$ if he chooses $q_{i}$ is $\int_{0}^{1} r\left(q_{i}, \nu\right) d \nu$. To prove that a deviation is not profitable we examine $\frac{\partial}{\partial q_{i}} \int_{0}^{1} r\left(q_{i}, \nu\right)$. But notice that $\int_{0}^{1} r\left(q_{i}, \nu\right) d \nu=\int_{0}^{q_{i}} r\left(q_{i}, \nu\right) d \nu$, and, because of the form of $r, \frac{\partial}{\partial q_{i}} \int_{0}^{q_{i}} r\left(q_{i}, \nu\right)=r\left(q_{i}, q_{i}\right)$ 
We shall show that $r\left(q_{i}, q_{i}\right) \leq 0$ whenever $q_{i}>\hat{q}_{i}$ and $r\left(q_{i}, q_{i}\right) \geq 0$ whenever $q_{i}<\hat{q}_{i}$. The former is true because, if $q_{i}>\hat{q}_{i}$ (note that by definition $q_{i} \in\left(\hat{q}_{w\left(q_{i}\right)+1}, \hat{q}_{w\left(q_{i}\right)}\right]$ ),

$$
r\left(q_{i}, q_{i}\right)=\frac{a}{k\left(w\left(q_{i}\right)+1\right)}=c^{\prime}\left(\hat{q}_{w\left(q_{i}\right)+1}\right) \leq c^{\prime}\left(q_{i}\right) .
$$

(This happens because an attempt by $i$ to increase $q_{i}$ above, say, $\hat{q}_{i-2}$ would bring it in an segment of $\nu$ where news gathering if profitable if there are at most $i-3$ outlets, but now there are $i-2$ and the additional monitoring cost does not cover the additional profit).

The latter is true because, if $q_{i}<\hat{q}_{i}$,

$$
r\left(q_{i}, q_{i}\right)=\frac{a}{k\left(w\left(q_{i}\right)\right)}=c^{\prime}\left(\hat{q}_{w\left(q_{i}\right)}\right) \geq c^{\prime}\left(q_{i}\right)
$$

(Conversely, reducing $q_{i}$ below $\hat{q}_{i}$ is a bad idea because this is a segment of $\nu$ where the additional monitoring cost is lower than the additional profit). 


\section{Additional Material: A Model with Market Seg- mentation}

The baseline model assumed that all voters are informed if there is at least one informative outlet. This may be unrealistic because it presupposes that people are willing to switch to a different outlet if their usual outlet does not have interesting news. The goal of the present section is to consider a more general model where some viewers are flexible (they are willing to switch to a different media source) and some are not. We also generalize the model to allow for heterogeneity among outlets in the strength of the commercial motive (we replace $a$ with $a_{i}$ ) and in the transaction costs (we replace $\tau$ with $\tau_{i}$ ). Finally, we now allow the possibility that the government censors the media as well as buying silence through "voluntary" capture.

\section{$5.1 \quad$ Model}

The setting is as in the baseline case, except for the following changes:

Politicians: As before, politicians may offer bribes $\left\{t_{i}\right\}_{i=1}^{n}$ to outlets. However, now there is an outlet-specific transaction $\operatorname{cost} \tau_{i}$ - out of a bribe of $t_{i}$, the outlet receives $t_{i} / \tau_{i}$. We take this transactions cost to be an exogenous feature of the institutional environment embedded in legal, ownership or regulatory structures. A higher $\tau_{i}$ corresponds to it being harder to bribe the media. With probability $1-\lambda$, the politician finds a way of silencing the media without offering a bribe (e.g. direct censorship).

The incumbent still cares about holding office: she gets $r$ if she is re-elected and zero otherwise. However, now this benefit $r$ is a random variable with support $[0, \infty)$ and cumulative distribution function $F$. 
Voters There is a continuum of voters $V=[0,1]$ with homogeneous preferences (but possibly heterogeneous information). They choose whether to re-elect the incumbent or a random challenger who is good with probability $\gamma$.

We divide voters in into two classes: a proportion $1-\varphi$ has a preferred outlet and buys it if and only if it carries informative news (inflexible viewers), while a proportion $\varphi$ will buy any outlet as long as it carries informative news (flexible viewers). As we shall see below, the proportion of flexible viewers is an important determinant of media capture. ${ }^{25}$

Media As in the baseline case, there is an exogenous probability $q$ that all outlets become informed if the incumbent is bad.

Each outlet $i$ is characterized by a natural market share $\sigma_{i}$ (with $\sum_{i} \sigma_{i}=1$ ). The idea of a natural market share is a simple way of bringing in issues of concentration. It can be interpreted as reflecting some underlying characteristic of a outlet which is attractive to some viewers and is fixed for the purposes of this analysis. We take it as fixed for the purpose of our analysis. However, clearly it is variable over the longer term, with entry and exit of outlets.

As in the baseline model, the payoff of a media outlet depends on the number of viewers it attracts multiplied by a factor which we call the "commercial motive". However, now this fact is outlet-specific, and it is denoted by $a_{i}$ for outlet $i$.

Putting this together, we can compute the expected payoff to outlet $i$ when there is a set $J$ of informative outlets. This is:

$$
\pi_{i}= \begin{cases}a_{i}\left((1-\varphi) \sigma_{i}+\varphi \frac{\sigma_{i}}{\sum_{j \notin J} \sigma_{j}}\right) & \text { if } i \in J \\ 0 & \text { if } i \notin J\end{cases}
$$

If outlet $i$ carries informative news, then it attracts all of its own inflexible viewers and a

\footnotetext{
${ }^{25}$ One might further complicate the problem by assuming that some voters do not read newspapers or that some voters always read the same newspapers whether or not it carries informative news. The presence of these groups would make it easier for the incumbent to keep the electorate uninformed (but it would not add much to the analysis because their behavior is somewhat similar to inflexible viewers).
} 
share of the flexible voters depending on how many other outlets are carrying news. For example, if it is the only outlet with news, then it gets all of the flexible voters.

\section{Timing}

1. The incumbent is in power and her type is $\theta$. If $\theta=b$, with probability $q$ all outlets acquire a verifiable signal $y_{i}=b$. Otherwise, they all observe non-verifiable signal $y_{i}=\emptyset$. With probability $1-\lambda$, all outlets are censored.

2. The random variable $r$, distributed on $[0, \infty)$ according to $\operatorname{CDF} F$, is realized and observed. The incumbent observes the vector of signals $\left\{y_{i}\right\}_{i=1, \ldots, n}$ and can propose bribes $\left\{t_{i}\right\}_{i=1, \ldots, n}$.

3. outlet $i$ knows what signals the other outlets have observed and it accepts or rejects the bribe $t_{i}$. If it accepts the bribe, it reports $\tilde{y}_{i}=\emptyset$, if it rejects the bribe it reports $\tilde{y}_{i}=b$.

4. Voter $v$ chooses which outlet to select according to his type (flexible, inflexible) and his market segment. A voter who chooses outlet $i$ observes $\tilde{y}_{i}$. Voter $v$ casts his vote for the incumbent or the challenger. The candidate who wins the election is in power for the second term.

As there is a continuum of voters, we should expect multiple perfect Bayesian equilibria. For analytic simplicity, we choose to focus on sincere voting: each voter computes the posterior probability that the incumbent is good, $\hat{\gamma}$. If $\hat{\gamma}>\gamma$, he votes for the incumbent. If $\hat{\gamma}<\gamma$, he votes for the challenger. ${ }^{26}$

\footnotetext{
${ }^{26}$ This is not an innocuous assumption: we should expect better political accountability with pivotal voting, because uninformed voters have an incentive to abstain (or cast their ballot at random). For a discussion of the difference between sincere voting and pivotal voting in political economy models of the media, see Prat and Stromberg [23].
} 


\subsection{Capture}

To bribe a media outlet, the incumbent must offer to compensate it for any profits that it forgoes by remaining silent. The minimized cost for a bad politician of buying sufficient media silence to gain re-election is given in: ${ }^{27}$

Proposition 8 There is a sincere equilibrium where the minimum cost for a bad incumbent to be re-elected is:

$$
C^{*}=\min _{J}\left((1-\varphi) \sum_{i \in J} a_{i} \tau_{i} \sigma_{i}+\varphi \sum_{i \in J} \frac{a_{i} \tau_{i} \sigma_{i}}{\sum_{j \notin J} \sigma_{j}+\sigma_{i}}\right)
$$

subject to

$$
\sum_{i \in J} \sigma_{i} \geq \min \left(1, \frac{1}{2(1-\varphi)}\right) \equiv s^{*}
$$

Proof. Begin with Stage 4. Given sincere voting, each voter uses the information he has to construct a posterior $\hat{\gamma}$ of the probability that the candidate's type is $g$ and votes for the incumbent if and only if $\hat{\gamma} \geq \gamma$. Conjecture that viewers observe each of the two possible signal realizations with positive probability (we will check later that this belief is correct in equilibrium). Then it must be that $\hat{\gamma}\left(\tilde{y}_{i}=b\right)<\gamma<\hat{\gamma}\left(\tilde{y}_{i}=\emptyset\right)$. This means that if $y=\emptyset$ the incumbent is always re-elected and if $y=b$ the incumbent is re-elected if and only if at least half of the viewers observe $\tilde{y}=\emptyset$.

At stage 3, suppose that outlet $i$ has been offered $t_{i}$ and it conjectures that a subset $J$ of outlets (including himself) will suppress their signal. His payoff is

$$
\pi_{i}= \begin{cases}a_{i}\left((1-\varphi) \sigma_{i}+\varphi \frac{\sigma_{i}}{\sum_{j \notin J} \sigma_{j}+\sigma_{i}}\right) & \text { if he rejects } \\ \frac{t_{i}}{\tau_{i}} & \text { if he accepts }\end{cases}
$$

Thus he accepts if and only if

$$
t_{i} \geq a_{i} \tau_{i}\left((1-\varphi) \sigma_{i}+\varphi \frac{\sigma_{i}}{\sum_{j \notin J} \sigma_{j}+\sigma_{i}}\right)
$$

\footnotetext{
${ }^{27} \mathrm{As}$ in the rest of the paper, we focus on pure-strategy equilibria.
} 
The total cost of suppressing the signal for subset $J$ is thus

$$
(1-\varphi) \sum_{i \in J} a_{i} \tau_{i} \sigma_{i}+\varphi \sum_{i \in J} \frac{a_{i} \tau_{i} \sigma_{i}}{\sum_{j \notin J} \sigma_{j}+\sigma_{i}}
$$

At stage 2, the incumbent chooses between leaving the media free or making sure that half of the voters are silenced. If he silences a subset $J$ the proportion of viewers who observe $\emptyset$ is

$$
\begin{cases}(1-\varphi) \sum_{j \in J} \sigma_{j} & \text { if } J \subset N \\ 1 & \text { if } J=N\end{cases}
$$

In order to suppress information for at least half of the voters, the incumbent must choose $J$ such that either

$$
\sum_{j \in J} \sigma_{j} \geq \frac{1}{2(1-\varphi)}
$$

or $J=N$. In concise form, we can write

$$
\sum_{j \in J} \sigma_{j} \geq \min \left(1, \frac{1}{2(1-\varphi)}\right)
$$

Thus, the cost minimization problem of an incumbent who wants to suppress the signal is as in the statement of the Proposition.

To understand Proposition 8, note that the equilibrium cost of silencing outlet $i$ is equal to the additional profit that the outlet would receive if it were to carry informative news instead:

$$
(1-\varphi) a_{i} \sigma_{i}+\varphi a_{i} \frac{\sigma_{i}}{\sum_{j \notin J} \sigma_{j}+\sigma_{i}}
$$

The first additional term is the forgone revenue from inflexible viewers. The second additional term, is the forgone revenue from (potential) flexible viewers: if the outlet deviates and rejects the incumbent's offer, it gets a share of flexible viewers equal to its initial share $\sigma_{i}$ boosted by a factor $\frac{1}{\sum_{j \notin J} \sigma_{j}+\sigma_{i}}$ that depends on the total share of outlets that are not silenced. The cost of capture is simply the summation over all outlets that are silenced in equilibrium. 
The constraint represents the requirement that at least $50 \%$ of viewers stay uninformed. If $\varphi \geq 1 / 2$, the incumbent needs to buy out the whole media industry. If instead $\varphi<1 / 2$, then she only needs to buy out a set of outlets that covers a share of (initial) viewership greater or equal than $\frac{1}{2(1-\varphi)}$. If all viewers are inflexible, then buying a share $s^{*}=\frac{1}{2}$ is sufficient.

It is clear from (2) what factors go into making it more costly to capture the media. First, it is more costly to capture the media when there is more commercialization as represented by higher $a_{i}$ and higher levels of commercialization as represented by $\tau_{i}$. More voter flexibility also makes it more expensive to buy off the media - it means that a greater market share needs to be bought. Also an increase in $\varphi$ results in a greater cost of capture. We summarize these results in:

Proposition 9 The cost of capture $C^{*}$ is an increasing function of the proportion of flexible viewers $\varphi$, and a non-decreasing function of the transaction cost $\tau_{i}$ and the commercial motive $a_{i}$ of each outlet $i$.

The comparative static on concentration is now more complicated. Let us restrict attention to settings where the transaction cost and the commercial motive is the same for all outlets: $a_{i}=a$ and $\tau_{i}=\tau$ for all $i$. We distinguish two cases, according to whether $\varphi \geq 0.5$.

If the proportion of flexible viewers is at least $50 \%$, the analysis is simple. A bad incumbent must buy out all outlets in order to guarantee re-election $\left(s^{*}=1\right)$. The cost of capture in expression (2) boils down to

$$
C^{*}=a \tau(1-\varphi+\varphi n)
$$

which is a linear function of the number of outlets. Hence, the situation is very similar to the baseline result. Indeed, if $\varphi=1$, the cost of capture is exactly the same as in Proposition 1, namely a $n$. 
If the proportion of flexible viewers is below 50\%, the relationship between media concentration and cost of capture is more complex. To make the problem tractable, we make a further simplification: initial shares are identical across outlet, $\sigma_{i}=\frac{1}{n}$. Then, a decrease in concentration is just an increase in $n$. The cost of capture becomes

$$
C^{*}=a \tau\left((1-\varphi) \frac{m}{n}+\varphi \frac{m}{n-m+1}\right)
$$

where $m \geq s^{*} n$.

However, if $\varphi<0.5$, a decrease in concentration may lead to a decrease in the cost of capture because of integer constraints. For instance, suppose that all viewers are flexible and there is only one outlet. The cost of capture is simply $a \tau$. However, if the outlet splits into two equal size outlets, the cost is reduced to $\frac{1}{2} a \tau$. This effect is due solely to an indivisibility problem. With only one outlet, the incumbent is forced to buy out the whole outlet. $^{28}$

Indeed, we can show that the effect disappears if integer constraints are not present. To see this, assume that we start from a situation where the constrain $m \geq s^{*} n$ is binding (this is approximately true when $n$ is sufficiently large). The cost of capture is

$$
C^{*}=a \tau\left((1-\varphi) s^{*}+\varphi \frac{s^{*} n}{\left(1-s^{*}\right) n+1}\right) .
$$

Now the cost of capture is strictly increasing in $n$ unless $\varphi=0$.

To summarize our results on concentration:

Proposition 10 Suppose $a_{i}=a$ and $\tau_{i}=\tau$ for all $i$ :

1. If $\varphi \in\left[\frac{1}{2}, 1\right]$, the cost of capture is strictly increasing in the number of independent outlets $n$;

\footnotetext{
${ }^{28}$ This is probably just an artifact of the model. In practice, the incumbent and the newspaper could reach a mutually beneficial agreement whereby the paper finds a way of reducing its readership to less than $50 \%$.
} 
2. Suppose $\varphi \in\left(0, \frac{1}{2}\right), \sigma_{i}=\frac{1}{n}$ for all $i$, and the constraint (3) is binding. Then, the cost of capture is non-decreasing in the number of independent outlets $n$.

The higher is the proportion of flexible viewers, the closer we are to the baseline model. Only in the case where all viewers are inflexible $(\varphi=0)$ does a decrease in concentration not increase the cost of capture.

\subsection{Political Outcome}

To determine whether the media is captured, the incumbent (if she is bad) compares the cost of silencing the media with the stochastic rent $r$ from holding office in period two. The media is captured when the rent is high. Thus, we have:

Proposition 11 Suppose that voting is sincere. Then

(i) The probability that a bad incumbent is revealed to voters is

$$
E=q \lambda F\left(C^{*}\right)
$$

(ii) Expected turnover is

$$
T=(1-\gamma) q(1-\lambda) F\left(C^{*}\right)
$$

and

(iii) Expected voter welfare is

$$
U=\left(2+(1-\gamma)\left(q(1-\lambda) F\left(C^{*}\right)\right)\right) \gamma
$$

The last result shows that the results described in Proposition 2 for the baseline case extend to this more complex set-up. Voter information, political turnover, and voter welfare are all increasing functions of the cost of capture, and hence, by Propositions 9 and 10, of transaction cost, commercial motive, and (with the proviso discussed above) concentration.

Moreover, political outcomes also depend, in an unsurprising way, on the monitoring technology $(q)$ and on direct censorship $(\lambda)$. 


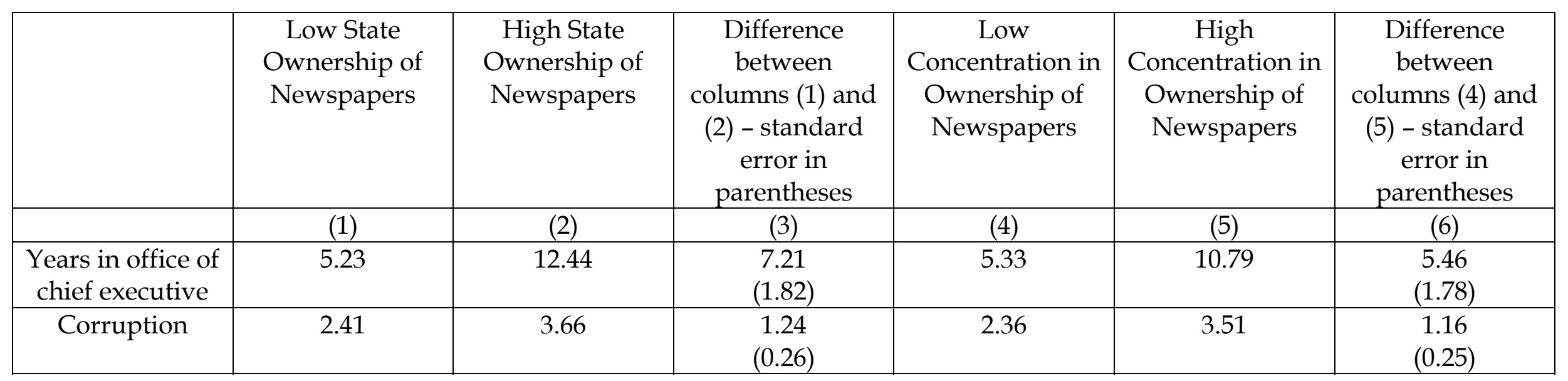

Notes: (1) All data are computed for a consistent sample of 88 countries for which all data are available - which is essentially the sample in Djankov et al (2004). (2) The number of years in office of the chief executive (typically Prime Minister or President) is taken from Beck et al (2000) and denotes the value as in 1997. The mean of this variable in our sample is 7.44 with a standard deviation of 8.53. (3) The corruption measure is from the International Country Risk Guide for 2001. The variable is measured on a seven point scale (0-6) where the highest level of corruption is 6 . The mean of this variable in our sample is 2.79 and the standard deviation is 1.28. (4) The measure of state ownership and concentration is from Djankov et al (2004). Low state ownership is defined as the state owning less than $30 \%$ of the market share among the top five newspapers in each country. The mean of state ownership of newspapers is $29.6 \%$. Concentration of ownership is a dummy variable equal to one if the top five outlets own more than $75 \%$ of the newspaper market regardless of the form of ownership. $39 \%$ of the sample of 88 countries in our sample are classified as concentrated by this measure.

Table 1: The Relationship between state ownership, concentration, turnover and corruption. 